\title{
APONTAMENTOS SOBRE A QUESTÃO DA TÉCNICA NO SÉCULO XX EM ABORDAGENS PRÉVIAS AO PENSAMENTO DE HANS JONAS
}

\author{
Remarks about questions related to technique in the 20th century in \\ previous approaches of Hans Jonas' thought
}

\author{
Geovani Viola Moretto Mendes \\ PUC-PR \\ Joelson Juk \\ IFPR
}

Resumo: A análise feita por Hans Jonas acerca do problema da técnica modema, se situou em una relação de identidade e diferenciaçăo para com a tradiçăo em que se encontrava inserido. Husserl foi um dos primeiros a indicar a necessidade de se reavaliar os limites da técnica modema, para ele o problema dessa técnica, por ser uma decorrência da matematização da natureza, seria a perda de uma capacidade de se produzir um conhecimento que nẵo seja intermediado pela própria tecnicidade da matematização. O trabalho de Ortega y Gasset na análise da técnica moderna, contribuiu para o estabelecimento de conceitos importantes, mas não suscitou uma reflexão crítica pertinente à contemporaneidade e nem apresentou grandes ressalvas quanto à utilizaçăo da técnica, pelo contrário, o filósofo espanhol foi um entusiasta dos resultados do tecnicismo. Martin Heidegger, é o filósofo anterior a Hans Jonas que com mais ênfase delineia não apenas uma análise da questão da técnica moderna, como também desenvolve uma crítica aos efeitos e as consequências que essa técnica pode produzir para a contemporaneidade. A partir dessas análises, é possível perceber que o pensamento de Hans Jonas é singular, sobretudo, porque vincula sua crítica e suas consideraçôes à técnica modema à análise do fenômeno da vida, preocupando-se em relacionar as ameaçs e os problemas dessa técnica com a concretude e a singularidade da vida.

Palavra- chave: Técnica - Hans Jonas - Ortega y Gasset - Husserl - Martin Heidegger.

\begin{abstract}
Hans Jonas' analysis about questions conceming modern technique is within a relation between identity and differentiation regarding the tradition in which these questions are placed. Husserl was the first theorist of the 20th Century to point out the necessity of reassessing the limits of modern technique. According to him, the controversy of this technique, once it occurs due to the mathematisation of reality, it would be the loss of an ability to develop a kind of knowledge which cannot be brokered for its own technicity of mathematisation. Examining modem technique, Ortega y Gasset's efforts contributed to establish important concepts, however, it did not evoke a critical reflection as regards the contemporaneity. Also, it did not present caveats as for the use of technique. Contrary to it, the Spanish philosopher was an enthusiastic of the outcomes of technicality. Martin Heidegger precedes Hans Jonas, he more emphatically outlines not only an analysis of questions connected to modem technique, but he additionally criticises the effects and consequences that this technique is able to produce to contemporaneity. From these studies it is possible to realise that Hans Jonas' thinking is remarkable, especially because he binds his considerations conceming modem technique to the phenomenon of life, trying to link the enquiries and threats inherent to technique to the concreteness and singularity of life.
\end{abstract}

Keywords: Technique - Hans Jonas - Ortega y Gasset - Husserl - Martin Heidegger.

\section{Introdução}

O presente texto será dedicado à análise do problema da técnica moderna, tal como Hans Jonas o apresenta. Nossa inntenção será reconstruir as análises do problema 
da técnica abordado por alguns filósofos influentes para o pensamento de Jonas, bem como pontuar de que modo seu pensamento se situou em uma relação de identidade e diferenciação para com a tradição em que se encontrava inserido. Buscando assim dar maior consistência para a própria análise de Hans Jonas, no presente texto, queremos reconstruir as principais abordagens sobre o problema da técnica moderna que antecederam as reflexões do filósofo do fenômeno da vida.

\section{A questão da técnica na filosofia do início do século XX}

O início do século XX é marcado por uma reflexão sobre os limites do projeto modemo, momento em que foi colocada em questão uma série de elementos que norteavam o pensamento filosófico. As bases da ciência haviam se alterado radicalmente com os novos avanços da física, da matemática, da biologia e da química, de modo que a estrutura de uma metodologia mecanicista (tal como havia sido apresentada por Newton) sofria uma grande alteração com teorias revolucionárias tais como a física quântica e a teoria da relatividade de Einstein. Em um certo sentido, questionava-se os limites do método científico moderno, como também se questionava as consequências legadas por esse método. A técnica era um dos elementos centrais, pois encontrava-se presente como uma instrumentalização desde o próprio começo do pensamento moderno, figurando com importância nas reflexões de Francis Bacon, de René Descartes, entre tantos outros filósofos.

Por essa razão, as primeiras décadas do século XX foram marcadas por uma revisão em diversas áreas - filosófica, cultural, política, social -, revisão essa que levou à colocação da questão sobre a técnica, não mais como simples instrumento, mas considerando as consequências e as repercussões deixadas pela relação entre a ciência/técnica e a natureza.

\section{Edmundo Husserl o esvaziamento do significado das ciências naturais matemáticas através da tecnicização}

Dentre os muitos pensadores que endereçaram questões ao problema da técnica está Edmundo Husserl, que foi um dos primeiros a problematizá-la justamente no epicentro de sua dificuldade, ou seja, como uma crise da ciência ocorre não apenas pelo esgotamento das metodologias antes concebidas, mas também em função dos resultados legados por essa apropriação da natureza, um movimento propriamente moderno.

Em sua obra, A crise das ciências europeias, Husserl volta sua reflexão para a maneira com que a ciência moderna apropriou-se da natureza por meio de um movimento conceitulal que permitia opor o sujeito cognoscente ao objeto conhecido, de tal modo que um dos resultados da separação sujeito-objeto teria por consequência a objetificação da exterioridade e, portanto, a objetificação da própria natureza. A análise de Husserl volta-se para o início da modernidade e encontra na abordagem matemática de Galileu Galilei as primeiras evidências de uma apropriação da natureza enquanto objeto. Segundo aponta Husserl:

Para o platonismo, o real tinha uma mais ou menos perfeita methexis [participação] no ideal. Isso proporcionou à geometria antiga as possibilidades de uma primitiva aplicação da realidade. Através da matematização da natureza de Galileu, a própria natureza é idealizada sob a orientação da nova matemática; a própria natureza se torna - para dizê-lo de maneira moderna - uma multiplicidade [Mannigfaltigkeit] matemática. (1970, p. 23)

É importante notar que Hüsserl começa sua reflexão apontando uma diferença essencial entre a abordagem matemática dos antigos (gregos, como a própria utilização de um termo grego indica) e a matemática dos modernos. Para os modernos, a 
matematização é a forma de apropriação da realidade, de determinação, portanto, da realidade sob a égide dos resultados e consequências fornecidas pela matemática.

As experiências sensíveis do cotidiano são dadas em uma maneira subjetivamente relativa, uma vez que cada indivíduo tem sua própria relação perceptiva com o mundo e, com base nessas experiências, traça sua própria produção de uma realidade efetiva. Essa diferença de percepções levaria ao que Husserl chama de "discrepância entre nossas validades ônticas", discrepância essa que é confrontada com o fato que, em termos externos, nós "necessariamente acreditamos no mundo", esse conceito que reuniria uma unidade de percepção, uma vez que as "coisas apenas aparecem para nós como diferentes", quando, em verdade, "são as mesmas" (1970, p. 23).

A pretensão de Galileu com o emprego da matematização é justamente essa de conferir uma unidade objetiva para as percepções inicialmente tomadas como subjetivas e várias. Partindo de uma geometria que tomaria os corpos como "espaços", "formas", "planos" ou "figuras", Galileu teria notado uma pretensa fallha nessa "práxis empírica", isto é, a falta de exatidão, que seria resolvida por uma "práxis matemática", onde haveria "a possibilidade de determinar as formas ideais em absoluta identidade, de reconhecêlas como substratos de absolutamente idênticas, inequívocas, metodológicas e determináveis qualidades" (1970, p. 27).

Por certo que essa metodologia apontada por Husserl tem uma consequência evidente aos olhos contemporâneos, isto é, a matematização da natureza corresponde à redução da natureza primeiramente a um objeto de análise abstrato, posteriormente a um objeto de análise "puro" e, finalmente, a um objeto de análise "controlável". Como considera Husserl, "tal matematização é pensável apenas no sentido que as qualidades sensíveis específicas ("plena") que podem ser experiência nos corpos intuídos, estão intimamente relacionadas em um modo peculiar e regulado com suas formas" (1970, p. 35).

É possível ver como a análise de Husserl leva a uma consideração crítica sobre o método de instrumentalização matemática da natureza e, portanto, da realidadle. Contudo, o próprio Husserl não avança sobre uma consideração crítica no que diz respeito aos limites de aplicação da técnica'. Sua intenção é voltar-se para o início de uma formulação teórica que seria responsável pela referida "crise das ciências europeias" identificadas por ele no começo do século XX. Parte de sula crítica mais veemente, nesse sentido, é voltada para a tecnicização da matemática, uma das muitas consequências do projeto de matematização da natureza. Para Husserl, dada como espécie de meta-movimento, a pretensão de matematização da natureza traz consigo, por seu emprego técnico na análise do mundo, a consequência de reduzir a própria matemática a uma técnica. A matemática torna-se a única forma legítima de analisar a natureza, promovendo um aprisionamento das possibilidades de percepção a uma condução pretensamente objetiva, mas ao mesmo tempo a própria matemática é aprisionada por sua tecnicidade.

Husserl afirma que esse movimento pode ser entendido como "o esvaziamento do significado das ciências naturais matemáticas através da tecnicização $0^{2 n}(1970, p .46)$. Esse esvaziamento, portanto, diz respeito tanto à maneira com que as ciências naturais foram desenvolvidas na modernidade, quanto à maneira que a natureza, ela mesma, foi abordada. Não interessa aqui pontuar toda a extensão da análise feita por Husserl, mas apenas pontuar que o filósofo alemão identificou no início da modernidade uma reviravolta conceitual que, segundo pontua-se, traz importantes resultados para forma com que a modernidade se relaciona com o mundo, com a exterioridade e, por

\footnotetext{
${ }^{1}$ Ao analisar o desenvolvimento da matematização da natureza realizada por Galileu, Husserl chega a afirmar que tal recurso à "geometria pura" e à matemática enquanto abstração foram, em verdade, resultados necessários para o desenvolvimento do avanço das consideraçôes científicas do cientista italiano, já que os recursos técnicos e instrumentais de seu tempo não permitiam avançar largamente com pesquisas meramente empíricas, tendo então de socorrer-se em elementos matemáticos

${ }^{2}$ Husserl emprega o temo Technisierung, que indica o movimento de tomar-se técnica, denotando aqui a passagen de um elemento diverso para a limitação da técnica noderna.
} 
conseguinte, com a natureza ${ }^{3}$. Essa análise de Galileu depois é estendida por Husserl a outros filósofos, tais como Descartes, Locke, Berkeley, Hume e Kant, onde as reflexões se alteram, mas a estrutura fundamental parece manter-se.

A análise e as posteriores reflexões de Husserl sobre a questão da técnica parecem ter exercido alguma influência sobre o pensamento de Hans Jonas. No capítulo intitulado Deus é um matemático?, incluído em O Princípio Vida, Hans Jonas, muito embora não mencione Husserl diretamente, acaba por remontar à base da reflexão husserliana, com menções a diversos pensadores e matemáticos, dentre os quais incluise, com certo destaque, o nome de Galileu e sua percepção de matematização da natureza. Hans Jonas reflete que:

Foi o interesse primordial pelo movimento, e não a satisfação com figuras, que ocasionou na física a ascensão do método algébrico: movimento, em vez de proporções espaciais fixas, passa a ser o principal objeto de medição. Isto indica uma atitude radicalmente nova. Nos primeiros tempos da ciência moderna a análise do devir substitui a contemplação do ser e é esta mudança que se encontra por tirás da intirodução da geometria analítica (...) Este desenvolvimento, em si interior à matemática, não deixou de ter aplicações na física. De fato, uma "natureza" diferente passava a poder ser investigada por uima matemática diferente. Pois o que dentro da esfera estritamente matemática aparecia como o estabelecimento de uma consideração funcional, em vez da consideração estática de objetivos intuíveis, quando aplicado ao campo da descrição física significava o dissolver as "formas substanciais" da ontologia clássica nos movimentos e forças elementares de que eram imaginadas (e experimentalmente demonstradas) como produto. (2004, p.90-91)

Nota-se uma proximidade entre as reflexões desenvolvidas por Husserl e aquelas que, posteriormente, realizaria Hans Jonas. Por certo que as intenções e as consequências diferem entre ambos os autores, mesmo porque Husserl não declara desenvolver a análise sob a pretensão e urgência de uma questão ética ${ }^{4}$. No entanto, a análise crítica sobre as origens da técnica moderna desenvolvida por Hans Jonas já está, de algum modo, indicada nas reflexões de Husserl.

\section{José Ortega y Gasset e a técnica como a reforma que o homem impõe à natureza em vista da satisfação de suas necessidades}

Outro autor que antecipou um movimento de questionamento sobre o problema da técnica, e que foi por muito tempo esquecido, é José Ortega y Gasset. Filósofo espanhol, de certa forma discípulo de Husserl, que escreveu em 1939 o texto Meditação da técnica, onde pela primeira vez a questão é abordada de maneira frontal quando o

\footnotetext{
${ }^{3}$ Parte relevante da análise de Husserl indica que Galileu, ao desenvolver sua metodologia por meio da matematização da natureza, partiu de uma idealizaçăo da realidade, mostrando-se um herdeiro da maneira com que os antigos relacionaram-se com a realidade através da geometria. Contudo, ao contrário dos antigos, Galileu não teria voltado a investigar a conquista original do sentido do fenômeno analisado, promovendo a idealização a um padrăo de realidade $\mathrm{e}$, com isso, condicionando a própria realidade à matematização e, portanto, à técnica (HUSSERL, 1970, p. 49).

${ }^{4}$ É preciso ressalvar que muito embora Husserl não indique, de forma explícita, uma necessidade de abordagem ética com relação ao problema da técnica, há em suas reflexões sobre a crise das ciências europeias já uma longa consideração sobre os problemas éticos. Nos textos voltados para a questão da Crise e Renovação da Europa, onde Husserl vê a premente necessidade de se abordar uma reconsideração ética com bases neokantianas, percebe-se o esforço por endereçar questões que deem conta de resolver o problema legado por essa "crise" dos valores e das ciências identificados pelo filósofo alemão. Essa reflexão, iniciada nos anos 1920, ou seja, já realizada quando Hans Jonas fora aluno de Husserl, permaneceu até os últimos textos, como é o caso de A crise das ciências europeias e A crise da humanidade europeia e a filosofia. Além disso, năo se pode ignorar que Husserl empregava, em seus esforços por uma abordagem ética, o termo "responsabilidade" (Verantwortung), termos posteriormente empregados por Hans Jonas em uma de suas mais célebres obras. Nesse sentido, cf. HUSSERL, 2014.
} 
autor afirma que "um dos temas que nos próximos anos será debatido com maior brio é o sentido, as vantagens, os danos e os limites da técnica" (1964, p. 319).

Ortega y Gasset faz com que a análise da questão se inicie por uma consideração da essencialidade do fazer humano no mundo, ou seja, da forma com que o homem relaciona-se consigo próprio e com a sua exterioridade. Em um texto que foi publicado conjuntamente com a Meditação da técnica, e que o antecedia em sua publicação, intitulado Ensimesmamento e Alteração, o filósofo espanhol havia indicado que toda ação parte necessariamente de uma contemplação $e$, portanto, de uma tendência de interioridade que antecederia toda ação futura (1964, p. 304).

Essa interioridade descarta qualquer possibilidade de que o fazer humano seja regrado unicamente pelo instinto, como Ortega y Gasset aponta em sua análise sobre a técnica ${ }^{5}$. O esquentar-se quando sente frio, o alimentar-se quando sente fome, o fato de que o homem busca satisfazer suas necessidades não corresponde a uma mera reação, mas passa por uma essencialidade atribuída pelo filósofo ao homem, isto é, uma disposição para relacionar-se com o mundo de modo a transformá-lo. A transformação, como logo evidencia Ortega y Gasset, se dá por meio da técnica, que permite produzir o fogo, que permite construir instrumentos e suprir as necessidades imediatas.

A relação que permite a criação da técnica é, nesse sentido, mediada pela natureza, que figura, em um primeiro momento, como aquela condição que não supria todas as necessidades do homem. Ao contrário dos animais, indica o filósofo espanlhol, os homens não estão perfeitamente servidos pela natureza, mas precisam agir por meio da técnica para produzir sua própria subsistência. Esses atos produzem a técnica em relação à natureza e para com a natureza. É por essa razão que Ortega y Gasset escreve que disso:

resuita que estes atos modificam ou reformam a circunstância ou a natureza, conseguindo que nela haja o que não há - seja o que não existe aqui e agora quando se necessita, seja o que em absoluto não existe. Pois bem, estes são os atos técnicos, específicos do homem, o conjunto deles é a técnica, que podemos desde logo, definir como a reforma que o homem impõe à natureza em vista da satisfação de suas necessidlades. (...) É, pois, a técnica, a reação enérgica contra a natureza ou circunstância que leva a criar entre esta e o homem uima nova natureza posta sobre aquela, uma sobrenatureza. $(1964$, p. 324)

A análise de Ortega y Gasset não apresenta, até este ponto, nenhuma novidade, seja com relação aos antigos - com a ideia de uma separação e, simultaneamente, uma vinculação entre o homem e a natureza - seja com relação aos modernos - pela ideia de transformação e apropriação da natureza. A técnica é a ação que "modifica" e "reforma" a natureza, e não o faz simplesmente em função das necessidades mais imediatas (como sobrevivência), mas o faz para a produção de algo que vai além dessa mera "condição natural". Esse "ir além" é atribuído por Ortega y Gasset como a produção do bem-estar.

Em uma posição existencialista à sula própria maneira, o filósofo espanhol diferencia o "estar" - atribuído às relações imediatas, naturais, instintivas e, portanto, naturais - e o "bem-estar" - produto humano de uma condição singular -, diferenciação essa que permite-lhe afirmar que "o bem-estar e não o estar é a necessidade fundamental para o homem, a necessidade de suas necessidades" (1964, p. 328). Importa-nos pouco desenvolver uma análise sobre as consequências existencialistas e existenciais que Ortega y Gasset pretende retirar do conceito de "bem-estar"; importa-nos, no entanto, pontuar que a técnica, primeiramente tomada como capaz de modificar e reformar a natureza para a produção de uma sobrenatureza, agora é pontuadla como capaz de

\footnotetext{
${ }^{5}$ Existe uma espécie de recurso dialético disposto entre o reconhecimento da necessidade exterior e o reconhecimento de um sentimento subjetivo em Ortega y Gasset. Com relação à análise da técnica, as necessidades humanas são entendidas como, simultaneamente, externas e interiormente percebidas. Isso a tal ponto que o filósofo pode indicar que "o homem reconhece esta necessidade material ou objetiva e porque a reconhece a sente subjetivamente como necessidade" (1964, p. 321).
} 
converter o supérfluo em necessário, já que "homem, técnica e bem-estar são, em últịma instância, sinônimos", como assevera o filósofo espanhol (1964, p. 329).

Trata-se, de certa maneira, de uma consideração propriamente moderna, pois parte da premissa que a natureza é dada ao homem para que este a sobreponha por meio da técnica. Pois há dois caminhos possíveis para o uso da técnica: "de um lado servir à vida orgânica, que é adaptação do sujeito ao meio, simples estar na natureza”, contudo, "de outro, servir à boa vida, ao bem-estar, que implica adaptação do meio à vontade do sujeito" (1964, p. 329). A limitação da técnica não é dada pela natureza, como nos antigos, nem tampouco é um limite definido por si mesmo, como poderia ser inferido de uma leitura matemática, mas é atribuída pelo sentido de "bem-estar" dado por Ortega y Gasset. É com esse sentido de "bem-estar", um tanto poético e tomado por uma formulação de certa maneira ética, que o filósofo espanhol afirma que "no vão que a superação de sua vida animal deixa, dedica-se o homem a uma série de tarefas não biológicas, que não lhe são impostas pela natureza, que ele inventa para si mesmo" e é justamente "essa vida inventada, inventada como se inventa um romance ou uma peça de teatro, é ao que o homem chama vida humana, bem-estar" (1964, p. 334).

O homem, oposto à natureza, apartado quase que totalmente do campo natural, diferenciado perante o natural, é então absolutamente distanciado da natureza por meio da técnica, a qual é regida pela ética de um "bem-estar". Ortega y Gasset aponta então o que ele considera como sendo os três estágios da técnica, estágios esses que correspondem a uma certa evolução da apropriação e da utilização que o homem fez da técnica. Os três estágios correspondem à "função técnica em geral" e estão divididos entre: a) a técnica do acaso; b) a técnica do artesanato; e c) a técnica do técnico $(1964$, p. 360 ).

A técnica do acaso é assim chamada por Ortega y Gasset porque corresponderia ao fato que o "acaso é nela o técnico, o que proporciona o invento", sendo essa considerada "a técnica primitiva do homem pré e proto-histórico". Para o autor, é uma técnica que ocorre sem percepção de si, já que "o hhomem primitivo ignora sua própria técnica enquanto técnica; não se dá conta de que entre suas capacidades há uma especialíssima que lhe permite reformar a natureza no sentido de seus desejos" (1964, p. 360).

A técnica enquanto produção artesã é considerada por Ortega y Gasset como sendo aquela "da velha Grécia, é a técnica da Roma pré-imperial e da Idade Média", ou seja, é a técnica ainda pré-moderna, um estágio que, segundo o autor, não foi capaz de singularizar a técnica de outros meios e outras produções. Para o filósofo, na técnica prémoderna "ainda a proporção entre o não técnico e o técnico não é tal que o técnico se tenha tornado a base absoluta de sustentação" (1964, p. 363).

Essa exigência de independência da técnica é justamente o que ocorre na idade moderna, onde ocorre que Ortega y Gasset chama de "o fabuloso crescimento de atos e resultados técnicos que integram a vida atual" (1964, p. 367). Na modernidade a técnica teria se separado das outras formas de atividades humanas, sendo isolada, reportandose agora a uma especificidade singular, onde a técnica é desenvolvida quase que exclusivamente pelo "técnico", ao qual Ortega y Gasset associa a figura do engenheiro ${ }^{6}$. É

\footnotetext{
${ }^{6}$ A forma com que Ortega y Gasset demonstra essa passagem da técnica pré-moderna para a técnica modema pode ser amplamente questionada. Dois elementos são centrais para o autor, a utillização e concepção de máquina como substituto do instrumento e a consequente aparição da figura do engenheiro como o técnico que não se confunde com o "mero" trabalhador. Nesse sentido escreve o autor: "O outro traço que leva ao homem a descobrir o caráter genuíno de sua própria técnica foi, dissemos, o trânsito do mero instrumento à máquina, isto é, ao mecanismo que atua por si mesmo. A máquina abandona em última instância o homem, o artesão. Não é já o utensilio que auxilia ao homem, mas ao contrário: o homem fica reduzido a auxiliar da máquina. Uma fábrica é hoje um artefato independente ao qual ajudam em alguns momentos uns poucos homens, cujo papel resulta modestíssimo. (...) Consequência disso foi que o técnico e o operário, unidos no artesăo, se separassem, e ao ficar isolado se convertesse o técnico enquanto tal na expressão pura, vivente, da técnica enquanto tal: em suma, o engenheiro" (1964, p. 368). É importante atentar para a inversão que a técnica produz na função do homem, já que, destaca-se, não é o utensilio que auxilia ao homem, mas é o homem que se vê 
aqui que o autor chega ao ponto crucial de sua análise, uma análise que revela traços essenciais da técnica moderna:

\begin{abstract}
Hoje está a técnica ante nossos olhos, tal e como é, ỉsenta, à parte e sem confundir-se e ocultar-se no que não é ela. Por isso se dedicam concretamente a ela certos homens, os técnicos. Na Idade paleolítica ou na Idade Média, o inventar não podia constituir um ofício porque o homem ignorava seu próprio poder de invenção. Hoje, pelo contrário, o técnico se dedica, como à atividade mais normal e pré-estabelecida, ao trabalho de inventar. Ao contrário do primitivo, antes de inventar sabe que pode inventair; isto equivale a que antes de ter uma técnica tem a técnica. Até este ponto e ainda neste sentido quase material é certo o que venho sustentando: que as técnicas são somente concreções a posteriori da função geral técnica do homem. O técnico não tem que esperar os acasos e submeter-se a ciffras evanescentes de probabillidade, já que, em princípio, está seguro de que chegará a descobrimentos. (1964, p. 368-369).
\end{abstract}

A análise de Ortega y Gasset é acurada quando às relações diferenciais estabelecidas pela técnica, como no caso de que a técnica moderna só se faz possível pela substituição entre o fazer e o fazer técnico, pela indicação de que a técnica se tornou uma questão de especialização e, portanto, de especialistas, e, principalmente, que a técnica moderna, contrariamente aos desígnios técnicos anteriores, desenvolve uma relação de domínio, modificação e alteração da natureza. O filósofo espanhol é preciso em sua análise, mas é, conjuntamente, um entusiasta dos resultados do tecnicismo, não apresentando, em seu ensaio, grandes ressalvas quanto à utilização da técnica.

Por tomar a vida humana como diferenciada de todo o restante da vida, e por assumir que compete ao homem produzir o seu próprio "bem-estar" em detrimento do restante do mundo e, portanto, valendo-se da natureza como um simples objeto, Ortega y Gasset desconsidera qualquer possibilidade de concepção ética sobre o uso da técnica. Muito embora sua análise sobre a técnica moderna mostre-se acurada, por ser capaz de dizer aquilo que a técnica moderna é, em sua manifestação, o filósofo não retira nenhuma consequência sobre essa análise $e^{7}$ Trata-se, portanto, de um importante trabalho por seu pioneirismo, mas não tanto por ter suscitado uma reflexão crítica pertinente à contemporaneidade.

\title{
4. Martin Heidegger e a técnica como um modo de desabrigar
}

Muito diversa e mais profunda é a análise sobre a técnica desenvolvida por Martin Heidegger em seu ensaio de 1954, A questão da técnica. Heidegger faz com que sua análise parta da pressuposição de que "a técnica não é a mesma coisa que a essência da técnica", pois da mesma forma que a busca pela essência da árvore, que visa alcançar - domínio da árvore enquanto árvore, não nos leva propriamente a uma árvore particular, também assim deve se proceder para com a técnica (2007, p. 375).

A análise da técnica, nesse sentido, não será voltada para a análise de algo técnico, mas busca considerar aquilo que a técnica é, sobretudo quando em sua manifestação moderna. Para tanto, Heidegger tem de demonstrar que a análise da essência da técnica tem que ultrapassar as determinações "ônticas" da técnica, determinações essas que são expressas, segundo o autor, por dois enunciados: a) a técnica é um meio para fins; e b) a técnica é um fazer do homem (2007, p. 376).

reduzido a um mero auxiliar da máquina. Essa mudança é crucial para entender a relação do homem modemo com a técnica.

${ }^{7}$ Em um outro sentido, Ortega y Gasset parece desenvolver uma crítica ao tecnicismo modemo, porém com relação à perspectiva social e política, como ocorre em seu escrito A Rebelião das Massas. Há em sua crítica uma manifestação de certo conservadorismo e um traço "aristocrático" que aproximaria o tom de sua crítica uma posição política perigosa. Para uma maior compreensão sobre a relação entre técnica e ética em Ortega y Gasset cf. GONÇALVES Jr., Arlindo Ferreira. Ética e sociedade tecnológica segundo a filosofia de Ortega y Gasset. In.: Reflexão. Campinas, 31(89), p. 25-39, jan./jun., 2006; e QUILES, 1991. 
Esses dois enunciados, no entanto, partem daquilo que está à frente, que nos é dado como evidente e imediatamente manifesto e, como ocorre com todas as manifestações imediatas, estas revelam um velamento que encobre a verdade, isto é, a essência, que se encontra velada e, portanto, precisa ser desvelada. A instrumentalidade assumida no enunciado de que a técnica é "um meio para fins" revela apenas que essa afirmação, embora possa ser correta de certa maneira, não revela a essência da técnica, revelando apenas uma espécie de estrutura menos elementar, ou seja, a relação de causalidade ${ }^{8}$. Heidegger volta sua questão para a análise da teoria das quatro causas com a intenção de demonstrar aquilo que a produção gerada pela técnica é capaz de nos revelar.

O produzir de uma taça de prata tem de partir, necessariamente, da materialidade da prata, manejada, alterada e convertida em uma forma específica, que determinará por sua vez a utilização ou finalidade da referida taça, finalidade essa que é dada pelo forjador que "efetua o efeito, a taça real acabada" (2007, p. 377). A conversão da materialidade da prata pura em uma forma específica que visa a produção de uma taça, gerada para uma finalidade determinada, revela o que Heidegger chama de comprometimento (Verschulden) dos modos causais. Não importa, para o filósofo alemão, deter-se em cada modo de causalidade, mas apenas demonstrar que algo acontece na passagem e na vinculação entre esses modos, isso é, algo acontece quando a prata toma a forma da taça, visada para uma finalidade específica. Segundo pontua Heidegger, "os quatro modos de comprometimento fazem com que algo apareça", pois "eles deixam algo surgir na pre-sença (An-wesen)" (2007, p. 379).

A produção de algo, portanto, é revelação dessa presença que se encontra oculta quando tomamos a técnica como mera instrumentalidade. Ao analisar o produzir de uma taça de prata, Heidegger demonstra que o comprometimento, ou seja, a relação entre a produção e o que é manifesto pela própria produção, acaba por evidenciar um desvelamento. O que a análise da técnica como mera instrumentalidade revela é o fato que essa instrumentalidade é um "desabrigar", sendo que isso corresponde não mais ao fato que a técnica é um simples meio para um fim, mas corresponde à essência da técnica (2007, p. 379-380).

Até esse ponto Heidegger vinha desenvolvendo uma análise que se ancorava em um pensamento grego e medieval, pois quis demonstrar que o comprometimento revelado no produzir técnico levava a uma apresentação da própria presença, ou seja, do fato que a prata convertida em taça evidencia a própria conversão e, nesse sentido, revela tanto a taça enquanto forma, como a prata enquanto materialidade. Com base nessa forma de reflexão é que Heidegger pode afirmar que a "técnica é um modo de desabrigar", e, portanto, que "a técnica se essencializa no âmbito onde acontece o desabrigar e o desocultamento" (2007, p. 381).

É nesse ponto, uma vez determinado um caráter essencial da técnica (ao menos como entendida ao modo grego e medieval e, assim, pré-moderno), que o filósofo alemão pode avançar para uma consideração sobre a técnica moderna:

Contra esta determinação do âmbito essencial da técnica podemos objetar que ela, na verdade, vale para o pensar grego e que, no mellhor dos casos, cabe para a técnica manual, mas não para a moderna técnica das máquinas de força. Mas, justamente esta técnica, esta mesma é que inquieta, o que nos leva a questionar "a" técnica. Diz-se que a técnica moderna é algo totalmente incomparável com todas as outras técnicas anteriores, porque ela repousa sobre a moderna ciência exata da natureza. Entretanto, reconheceu-se com mais clareza que também o inverso é válido: a física moderna, como algo que é experimental, depende de

\footnotetext{
${ }^{8}$ Não cabe aqui remontar todo o argumento heideggeriano sobre as quatro causas (causa materialis, causa formalis, causa finalis, causa efficiens). Importa apenas indicar que a apropriaçăo que faz Heidegger do problema da causalidade busca revelar algo que está além da concepção original empregada pelos filósofo medievais, aos quais Heidegger faz menção velada, bem como à Aristóteles, mencionado por Heidegger brevemente em sua análise.
} 
aparelhos técinicos e do progresso da construção de aparelhos. A verificação dessa relação mútua entre técnica e física é correta. Ela permanece, porém, uma mera verificação histórica de fatos e não diz nada sobre onde se fundamenta essa relação mútua. Contudo, a questão decisiva permanece: de que essência é a técnica moderna para que incorra no emprego da ciência exata da natureza? (2007, p. 381).

A técnica moderna é também um desabrigar, mas ela o é, segundo aponta Heidegger, de uma forma diferente. O desabrigar da técnica moderna "não se desdobra num levar à frente", não é uma produção no sentido antes entendido. De forma diversa, "o desabrigar imperante na técnica moderna é um desafiar que estabelece, para a natureza, a exigência de fornecer a energia suscetível de ser extraída e armazenada enquanto tal" (2007, p. 381). Esse é um ponto central da análise de Heidegger sobre a técnica moderna, isto é, o fato de que a natureza foi reduzida, em função da técnica, em um objeto de extração e armazenamento de energia. Contrariamente à maneira prémoderna de se relacionar com a natureza, a modernidade teria apresentado uma nova forma de relação, determinada por uma capacidade de pôr (stellt) a natureza, como pontua Heidegger (2007, p. 381-382). A consequência desse pôr a natureza é o estabelecimento de uma nova forma de relação:

O pôr que desafia as energias naturais é um extrair em duplo sentido. É um extrair na medida em que explora e destaca. Este extrair, contudo, permanece previamente disposto a exigir outra coisa, isto é, impelir adiante para o máximo de proveito, a partir do mínimo de despesas. O carvão extiraído da reserva mineral não é posto para que esteja, apenas em geral e em qualquer lugar, à mão. Ele é armazenado, isto é, posto para a encomenda do calor solar que nele está estocado. O calor solar é extraído para o calor que está encomendado para gerar vapor, cuja pressão iimpele a engrenagem por meio da qual a fábrica permanece operando. (2007, p. 382)

A natureza não é simplesmente convertida em um objeto; mais do que isso, a natureza é, na modernidade, colocada em função da técnica. Heidegger vale-se de um exemplo que, por sua potência imagética, recebeu notoriedade na consideração sobre a técnica moderna: ao se instalar uma hidrelétrica no rio Reno, este agora não é mais o centro da relação, como ocorreria com uma ponte, mas o rio é convertido "em função da pressão de suas águas" (2007, p. 382), caracterizando-se assim a inversão da relação.

A técnica moderna tem uma posição (Stand) própria que se revela no caráter de subsistência (Bestand). A subsistência é o que se percebe em função da extração e conservação da natureza, ou, como o filósofo pontua, "aquilo que subsiste no sentido da subsistência não nos está mais colocado diante de nós como umm objeto" (2007, p. 383). O rio não está mais colocado diante de nós como rio porque a natureza, ela mesma, não está mais colocada diante de nós como natureza, mas apenas enquanto algo que é posto pela técnica. A subsistência, entendida como o não por a natureza como objeto, se estende também ao homem, já que a técnica moderna é um desafio não apenas para a natureza, mas o é também para o homem, porém năo o faz de tal maneira que seja capaz de converter o homem em subsistência. Para Heidegger, porque "o homem é desafiado mais originariamente do que as energias naturais, a saber, no requerer (Bestelle), ele nunca será mera subsistência", contudo, "na medida em que o homem cultiva a técnica, ele toma parte no requerer enquanto um modo de desabrigar" (2007, p. 384). Esse ponto traz duas consequências: a) a técnica moderna não é um mero fazer humano; b) há algo na técnica moderna que ocorre apesar do homem e de modo alheio ao homem.

\footnotetext{
${ }^{9}$ A análise fillosófica se realiza por um meio cuidadoso com a linguagem e com o uso de termos e conceitos, como ocorre na análise da técnica com o verbo alemão stellt, que será o centro de toda a condução de sua análise. É importante pontuar que esse pôr da técnica moderna é uma inversão na relação com a natureza, pois esta já não se encontra mais dada - como ocorria na era pré-modema -, mas é agora posta, o que significa que ela é colocada em funcão da própria técnica.
} 
Uma vez que Heidegger pode afastar os enunciados usualmente concebidos à técnica (de que esta é um meio para fins, e que é um fazer do homem), ele tem de encontrar algo que vincule o homem ao fazer técnico propriamente moderno. Para o filósofo, "aquela invocação desafiadora que reúne o homem a requerer o que se descobre enquanto a subsistência" é chamada de "armação (Ge-stell)" (2007, p. 384).

Armação é a relação do pôr, uma forma de vinculação própria da relação entre objetos, sobretudo no que diz respeito ao encadeamento que deve ser evidenciado na produção de um objeto, porém é também um traço essencial da técnica moderna. Como afirma Heidegger, "armação significa a reunião daquele pôr que o homem põe, isto é, desafia para desocultar a realidade no modo do requerer enquanto subsistência", de tal modo que "armação significa o modo de desabrigar que impera na essência da técnica moderna e não é propriamente nada de técnico" (2007, p. 385). A armação (Ge-stell) tem relação com a palavra pôr (stellen), mas também possui uma vinculação com o produzir (Her-stellen) e com o ex-pôr (Dar-stellenn). O produzir é um expor no sentido de que leva à frente, de que faz aparecer e desoculta o que vinha velado. A armação, por sula vez, como essência da técnica moderna, é justamente aquilo que inviabiliza o levar à frente, de tal modo que "o traballho da técnica moderna desabriga o real enquanto subsistência" (2007, p. 385).

Nesse ponto Heidegger dirige sua atenção para o que permitiu à técnica moderna estabelecer essa armação enquanto fechamento do levar à frente do real. Para ele, isso ocorre por um processo propriamente moderno que se inicia com a ciência natural matematizada, uma vez que "a técnica moderna somente entrou em curso quando ela pôde apoiar-se sobre a ciência exata da natureza" (2007, p. 386). Da mesma forma ocorre com a física da natureza, tomada como uma preparação para a essência da técnica enquanto modo de relacionar-se com a natureza. Uma vez que a essência da técnica repousa na armação, uma armação que vale-se da matematização produzida pelas ciências naturais e que, por isso, reduz à natureza ao encadeamento que impede o desvelamento do real, o homem está posto em perigo. Se a essência da técnica não é um fazer humano, e o próprio homem é atravessado pela técnica enquanto armação, então a técnica moderna põe o homem em perigo, pois impede de reenviá-lo àquilo que ele é.

A armação pode ser vista, por exemplo, na figura da produção do cálice de prata. A produção da técnica pré-moderna disporia da prata em função do cálice, mas em nenhum momento isso inviabilizaria o reenvio ao fato que o cálice de prata é, em sua materialidade primeira, o fazer de algo com a prata. Ocorre que, na técnica moderna, é justamente esse reenvio que se vê prejudicado, pois uma cadeira não reenvia à árvore que foi eventualmente cortada na natureza, mas é a própria natureza que é convertida em extração em armazenamento em função da produção de cadeiras. Isso ocorre evidentemente na fabricação de carvão, na conversão de um rio em produção de energia hidroelétrica e assim sucessivamente. O fazer da técnica moderna, segundo Heidegger, impediria o desocultamento, o que valeria tanto para a natureza quanto para o homem:

Tão logo o que estiver descoberto não mais innteressar ao homem como objeto, mas exclusivamente como subsistência, e o homem no seio da falta de objeto apenas for aquele que requer a subsistência, - o homem caminhará na margem mais externa do precipício, a saber, caminhará para o lugar onde ele mesmo deverá apenas ser mais tomado como subsistência. Entretanto, justamente este homem ameaçado se arroga como a figura do dominador da terra. Desse modo, amplia-se a ilusão de que tudo o que vem ao encontro subsiste somente na medida em que é algo feito pelo homem. Esta ilusão torna madura uma última aparência enganadora. (2007, p. 389-390).

A análise de Heidegger sobre a técnica moderna é mais profunda que as antecedentes, pois vai além das meras determinações imediatas do fazer técnico, mas considera a essência da técnica e sua relação para com o homem. Contudo, há que se pontuar, que a ameaça ou o perigo identificados por Heidegger conlhecem um limite muito pontual, isto é, o limite que é o centro de seu fazer filosófico desde Ser e Tempo. o 
esquecimento da pergunta pelo Ser. Para Heidegger, a ameaça da técnica moderna é a produção de uma condição em que o homem é apanhado por um perigo de ver inviabilizada a possibilidade de poder novamente encontrar a abertura para a pergunta pelo Ser, tomada pelo filósofo alemão como o destino do homem. A crítica de Heidegger se sustenta na afirmação de que "o homem de hoje, na verdade, justamente não encontra mais a si mesmo, isto é, não encontra mais sula essência" (2007, p. 390).

Na análise feita por Heidegger sobre a técnica moderna há uma preocupação ontológica, mas não há o endereçamento à formulação de uma questão ou de uma possibilidade de questionar ético. Uma vez que a preocupação essencial é para com a essência do homem em um nível ontológico - a pergunta pelo Ser -, a técnica é uma ameaça apenas neste nível ontológico e qualquer forma de perigo não recebe uma fundamentação ética.

\section{Hans Jonas: limites e restrições das abordagens prévias à questão da técnica}

Há nas análises prévias sobre a questão da técnica moderna uma série de elementos de proximidade para com as considerações de Hans Jonas. Contudo, é justamente na diferenciação da análise que faz Hans Jonas com relação ao fundamento do problema da técnica que repousa a originalidade de sua reflexão.

É certo que as influências de Husserl e Heidegger são evidentes e possível de serem mapeadas no pensamento de Hans Jonas, enquanto a relação com Ortega y Gasset se dá apenas no plano das aproximações filosóficas. Como foi demonstrado, os três autores apontados analisam a técnica moderna como uma diferenciação perante à técnica pré-moderna, fazendo notar que a modernidade é pautada por uma alteração na relação do homem para com a natureza, alteração essa que passa a dispor a própria natureza como alvo de tratamento, de modificação, de extração e de controle.

Os efeitos surtidos pela matematização das ciências humanas é um dos pontos identificados, por Husserl e Heidegger em maior conta, mas também por Ortega y Gasset, como sendo um traço essencial que possibilita o advento e o acontecimento da técnica moderna. Além disso, também pontuam os autores que a passagem para a modernidade é marcada pela produção de máquinas como substitutos dos instrumentos, substituição que engendra uma nova forma de relação do homem para com o seu fazer técnico e, ao fim, para consigo próprio.

Os pontos identificados pelos três autores mencionados, são relevantes e geram, de forma mais evidente em Husserl e em Heidegger, o ensaio de uma crítica sobre a posição e o perigo da técnica moderna. Em Husserl é, uma questão de crise das ciências, quando muito chegando a um problema de valoração cultural europeia. Em Heidegger, por sua vez, a crítica é mais profunda e ampla, considerando que o problema da técnica moderna repousaria, sobretudo, na manifestação de um modo de ser que inviabilizaria a abertura de outros modos de ser, que seria o encerramento do que Heidegger julga como essencial ao humano, isto é, o desvelamento da pergunta pelo Ser.

Hans Jonas, por sua vez, aproxima-se dos autores mencionados com relação a parte dos pressupostos e dos resultados de suas análises, mas toma caminhos absolutamente diferentes quando observa o que ele considera como o verdadeiro problema e perigo da técnica moderna.

As reflexões de Husserl e Heidegger se dão em um plano demasiado intelectualizado - no sentido auto-reflexivo - e demasiado antropocêntrico. Ao fim, a preocupação com conceitos como "mundo da vida", "ser-para-morte" e "ser-no-mundo" possuem, de uma ou outra forma, um horizonte humano ${ }^{10}$. O Ser heideggeriano não tangencia um problema com todas as vidas e a natureza não é tomada como uma

\footnotetext{
${ }^{10}$ Muito embora esse possa soar como um ponto controverso, dado que os conceitos referidos - Lebenswelt, de Husserl; Sein-zum-tode e In-der-Welt-sein, de Heidegger - são engendrados sob uma tutela filosófica mais ampla, como é o caso do Daseinheideggeriano, que não se confunde, necessariamente, com o Homem no sentido específico, ainda assim é inegável que o ente para o qual se dá a abertura de pergunta pelo sentido do Ser tem de ser e é o homem.
} 
questão de posição sobre o problema da vida. Na análise feita por Husserl, por exemplo, a matematização da natureza não faz distinção entre uma "natureza animada" e uma "natureza inanimada", de tal modo que sua preocupação é para com a fundamentação das ciências em um sentido puramente antropológico. Com Heidegger a preocupação com a natureza é igualmente distante, já que o filósofo alemão menciona o tratamento com árvores, com rios, com paisagens, mas não parece preocupar-se com as questões biológicas ${ }^{11}$. Mesmo a preocupação ontológica de Heidegger é, de certa forma, antropocêntrica, pois considera o Ser em relação a uma pergunta filosófica, e não em relação a sua existência concreta mais eminente.

É nesse ponto que Hans Jonas diferencia-se das análises prévias feitas sobre a técnica e, ao mesmo tempo, apresenta uma posição capaz de retirar novas consequências e avançar em determinadas considerações. Como a base do pensamento de Hans Jonas parte de uma concepção ontológica da vida, uma concepção que é obtida por meio de uma análise fenomenológica, o natural é tomado de forma particular e encontra-se no epicentro de seu pensamento como uma vinculação ao problema da vida. Para Hans Jonas, a determinação ontológica da vida é o que deve delimitar qualquer análise sobre a técnica:

De todas as polaridades mencionadas, a do ser e não-ser é a mais fundamental. A ela a identidade é arrancada em um esforço supremo e persistente por adiar o final, que não obstante já está predeterminado. Pois o não-ser tem a seu favor a universalidade ou igualdade de todas as coisas. A resistência que o organismo The oferece tem que terminar na submissão, em que o ser-ele-mesmo desaparece e jamais retorna como este ser único. $O$ fato de a vida ser mortal constitui sua contradição básica, mas este fato é parte inseparável de sua essência, sem que seja possível sequer imaginar-se que seja possível suprimi-lo. A vida é mortal, não apesar de ser vida, mas precisamente porque é vida segundo sua mais primitiva constituição, pois a relação de forma e matéria em que ela se baseia é desta espécie revogável e inafiançável. (2004, p. 15).

Os limites e restrições das análises prévias sobre o problema da técnica moderna repousariam justamente no fato que tais análises não considerariam esse traço ontológico da vida, a oposição entre ser e não ser que se revela no organismo e que dimensiona a nossa própria condição de existência, mas também toda a condição existencial da vida. Hans Jonas, segundo Marie-Geneviève Pinsart, escapa de uma acusação de antropomorfismo, pois "em sua análise interpretativa do fenômeno da vida, ele amplia os ensinamentos da experiência do próprio corpo para a compreensão de todas as formas de vida" (2002, p. 91). O traço ontológico fundamental seria encontrado, nesse sentido, no organismo vivo, uma vez que "uma fundamentação ontológica é baseada na qualidade que pertence inseparavelmente ao ser de algo, como o metabolismo pertence ao organismo, exclusivamente a isso e a nenhuma outra coisa" (1996, p. 101).

Hans Jonas não nega um traço próprio ao ser humano no epicentro de sua reflexão, mas tal relação para com o homem se dá sempre na vinculação e no pertencimento do homem à natureza, à vida e, portanto, à própria dinâmica ontológica. Existe um movimento que vai do homem à vida/natureza e da vida/natureza ao homem que faz revelar os principais elementos das principais considerações filosóficas de Hans Jonas não somente sobre a técnica, mas também sobre a ética, sobre o fenômeno da vida e outras questões relativas. Como pontua Carl Mitcham, "para Jonas, a continuidade do metabolismo como uma base ontológica para toda vida permite com que a subjetividade seja perfectibilizada nos humanos para que seja lida em um retorno às outras formas

11 É suficientemente conhecida a tese de Heidegger que diferencia o homem dos animais e do mundo inorgânico pela posição com relação ao "mundo". Para o fillósofo, a pedra não tem mundo, o animal é pobre de mundo e homem é formador de mundo. Essa tese encontra repercussão no tratamento que dá Heidegger ao problema da vida, uma vez que ele não a considera, verdadeiramente, como o epicentro de sua questão ontológica. Nesse sentido cf.HEIDEGGER, 2003. 
orgânicas primitivas" (2010, p. 506). O esforço de Hans Jonas é, precisamente, demonstrar que o ser humano deve ser sempre considerado dentro do âmbito ontologicamente mais abrangente do fenômeno da vida e que não há ruptura entre o homem e os demais seres vivos. Isto o filósofo da vida demonstra pelo traço de interioridade reconhecido em seus vários níveis e que não é senão o próprio reconhecimento do fundo vital em nós mesmos, ou de nós mesmos ao fundo vital, ao qual pertencem todos os demais seres.

Essa relação entre a vida humana - a existência humana - e a vida orgânica como um todo não perfaz as indagações filosóficas de Heidegger e Husserl, por exemplo, e justamente por isso suas análises sobre a técnica moderna é limitada a uma apreensão determinada por uma perspectiva antropocêntrica. Nesse sentido, o caminho trillhado por Hans Jonas vislumbra uma antropologia que sustenta o aspecto epistemológico da autoexperiência realizada por meio do corpo, ao mesmo tempo em que mantém a continuidade e a unidade do âmbito ontológico identificado no fenômeno da vida. Por basear-se em uma reflexão ontológica sobre a vida, Hans Jonas pode desenvolver uma análise e uma leitura única sobre a técnica moderna, uma interpretação que revela um perigo único apresentado por essa manifestação da técnica e, ao mesmo tempo, uma análise que leva à abertura de uma exigência ética, exigência essa que não se encontra dada nas reflexões anteriores sobre a técnica. A diferença de Hans Jonas, nesse sentido, não é somente a formulação de uma ética com base na ameaça que a técnica moderna oferece à vida, mas é a vinculação analítica entre uma ontologia da vida baseada na estrutura do organismo que abre uma forma de leitura única com relação ao problema da técnica moderna e que, por sua vez, sugere uma abertura para a problemática da ética e da responsabilidade.

\section{Considerações finais}

O início do século XX é marcado por uma crise do pensamento que denota a necessidade de uma revisão de várias áreas do conhecimento, sendo que uma dessas áreas é justamente aquela voltada ao problema da técnica. Foi Husserl o primeiro a indicar a necessidade de se reavaliar os limites da técnica moderna, pontuando, em alguns de seus escritos, que a mudança ocorrida na passagem para a modernidade, realizada sobretudo por uma tendência de matematização da Natureza, permitiu que, ao mesmo tempo, se formulasse uma metodologia científica diferenciada e uma nova disposição sobre o alcance e o poder da técnica. Ao retirar a técnica dos limites da Natureza, colocando-a acima da técnica por um ato de abstração, Husserl reconlheceu que a própria Natureza era posta como "objeto de conhecimento" e, portanto, como algo dado à possibilidade de alteração e de aniquilamento da técnica moderna.

Husserl, no entanto, não desenvolveu uma crítica para além dos detalhes conceituais e metodológicos e tampouco considerou o impacto concreto da técnica moderna sobre o fenômeno da vida. Ortega y Gasset, no entanto, já conseguiu apontar com clareza essa alteração, inclusive indicando o fato de que, ao tomar a técnica como um diferencial frente à Natureza, o homem se coloca acima e fora da própria Natureza, não mais reconhecendo-se com o fenômeno da vida, mas julgando-se como um ente à parte desse âmbito. Embora a análise de Ortega y Gasset tenha sido importante por seu pioneirismo, também essa não possui um tom crítico suficiente, fornecendo conceitos e perspectivas importantes, mas não operando como uma verdadeira e detalhada crítica da técnica moderna.

Martin Heidegger, por sua vez, é o filósofo anterior a Hans Jonas que com mais ênfase delineia não apenas uma análise da questão da técnica moderna, como também desenvolve uma crítica aos efeitos e as consequências que essa técnica pode produzir para a contemporaneidade. A análise e a crítica heideggerianas, baseadas nos conceitos formulados pelo próprio filósofo e, então, limitadas por um questionamento ontológicometafísico, forneceram um instrumental importante para as considerações futuras, mas restringiram a crítica ao campo de questionamento a respeito do problema do Ser e, mais 
especificamente, da essência da técnica, considerada como um modo próprio de desvelamento que acabou por levar a um maior ocultamento ontológico.

Com base nessas análises, é possível perceber a singularidade do pensamento de Hans Jonas e notar a inovação que o filósofo da trouxe, sobretudo porque vincula sua crítica e suas considerações à técnica moderna à análise do fenômeno da vida, preocupando-se em relacionar as ameaças e os problemas dessa técnica com a concretude e a singularidade da vida. Dessa forma, sua análise sobre a técnica moderna, demonstra o caráter de engendramento e de vinculação com o problema do fenômeno da vida.

Formando-se em uma escola de caráter existencial evidentemente demarcado, como é o caso de seus mestres Husserl e Heidegger, Hans Jonas não pode negar a necessidade de se considerar o homem com relação à sua própria existência e ao pertencimento ao mundo em que habita, contudo, por considerar que não se pode limitar a análise filosófica aos termos de uma análise existencial, Jonas toma para si a questão pertinente ao fenômeno da vida, por um lado, e uma análise sobre o problema da técnica moderno, por outro lado.

O entrecruzamento entre esses dois campos, faz com que Jonas tenha de encontrar um ponto de ligação e unidade que lhe permita transitar entre um e outro campo de análise. Esse ponto de ligação é a ética, não mais tomada simplesmente como um exercício de estabelecimento de mandamentos ou imperativos para as ações humanas em relação ao âmbito estritamente infra-humano, mas intrahumano como uma disposição principiológica que coloca o homem em relação ao mundo que habita, a situação histórica em que se encontra (a técnica moderna), bem como a sua disposição em relação a si mesmo.

Eis como se alcançou, portanto, aquilo que estava previsto como objetivo central de nosso trabalho: demonstrou-se a especificidade do pensamento de Hans Jonas e como sua análise do problema da técnica no século XXI, diferencia-se das análises prévias.

\section{Referências}

ARENDT, Hanna et al. Sobre Heidegger. cinco voces judías. Trad. Bernardo Ainbinder. Introducción de Franco Volpi. Buenos Aires: Manantial, 2008.

BACON, Francis. Novum Organum ou verdadeiras indicações acerca da interpretação da natureza. Tradução e notas de José Aluysio Reis de Andrade. São Paulo: Nova Cultural, 1999b.

BECCHI, P. La vulnerabilità dela vita: contributi su Hans Jonas. Napoli: La Scuola di Pitagora $\mathbb{E}$ ditrice, 2008.

COMÍN, I. G. Introducción. In: Más acerca del perverso fin y otros diálogos y ensayos. Tradução de Illana Giner Comin. Coleción Clásicos del Pensamento Crítico. Madrid: Catarata, 2001.

- Introducción a la edición española. In:

Hans Jonas: poder o impotência de la subjetividad. Tradução de Illana Giner Comin. Coleção Pensamento Contemporâneo. Barcelona/Buenos Aires/México: Paidós, 2005.

DUPAS, Gilberto. Ética e poder na sociedade da informação. De como a autonomia das novas tecnologias obriga a rever o mito do progresso. São Paulo: Editora Unesp, 2000.

FUKUYAMA, F. Nosso futuro pós-humano: consequências da revolução da biotecnologia. Tradução de Luiza Borges. Rio de Janeiro: Rocco, 2003.

GALIMBERTI, U. Psiche e techne: o homem na idade da técnica. Tradução de José Maria de Almeida. São Paulo: Paulus, 2006. 
GIACOIA JUNIOR, O. Hans Jonas: o princípio responsabilidade - Ensaios de uma ética para a civilização tecnológica. In: OLIVEIRA, Manfredo (Org.). Correntes fundamentais da ética contemporânea. Petrópolis: Vozes, 2000.

HEIDEGGER, Martin. A questão da técnica. In: ___ Ensaios e conferências. Trad. Emmanuel Carneiro Leão, Gillvan Fogel, Márcia Sá Cavalcante Schuback. 5. ed. Petrópolis: Vozes; Bragança Paulista: Editora Universitária São Francisco, 2008. (Col. Pensamento Humano).

HEIDEGGER, Martin. A questão da técnica. In.: Scientiae Studia. São Paulo, v. 5, n. 3, p. 375-398, 2007.

HEIDEGGER, Martin. Os Conceitos Fundamentais da Metafísica: Mundo, Finitude, Solidão. Rio de Janeiro: Forense Universitária, 2003.

HUSSERL, Edmund. Europa: Crise e Renovação. Rio de Janeiro: Forense Universitária, 2014.

HUSSERL, Edmund. The crisis of European Sciences and Transcendental Phenomenology. Evanston: Northwestern University Press, 1970.

JONAS, Hans. Matéria, espírito e criação: dados cosmológicos e conjecturas cosmogônicas. Tradução de Wendell Evangelista Soares Lopes. Petrópolis: Vozes, 2010.

Memorias. Traducción de Illana Giner Comín. Madri: Editorial Losada, 2005.

Mortality and morality: a search for the good after Auschwitz. Northwestern University studies in phenomenology \& existential philosophy. A collection of essays edited by Lawrence Vogel, 1996.

O princípio responsabilidade: ensaio de uma ética para a civilização tecnológica. Tradução de Marijane Lisboa e Luiz Barros Montez. Rio de Janeiro: Contraponto; Editora PUC-RJ, 2006.

O princípio vida: fundamentos para uma biologia filosófica. Tradução de Carlos Almeida Pereira. Petrópolis: Vozes, 2004. Helder, 1998.

Pensar sobre Dios y otros ensayos. Tradução de Ângela Ackermann. Barcelona:

LOPES, Wendell Evangelista Soares. A fundamentação metafísica do princípio responsabilidade em Hans Jonas. 1998. 140 f. Dissertação (Mestrado em Filosofia) Faculdade Jesuíta de Filosofia e Teologia, 1998.

MITCHAM, Carl. Qué es la filosofía de la tecnología? Barcelona: Anthropos, 1989.

OLIVEIRA, J. R. Da magnitude e ambivalência à necessária humanização da tecnociência segundo Hans Jonas. Cadernos do Instituto Humanitas Unisinos, ano X, n. 176, 2012a.

ORTEGA Y GASSET, J. Meditação sobre a técnica. Tradução e prólogo de Luis Washington Vita. Rio de Janeiro: Livro Ibero-Americano, 1963.

ORTEGA Y GASSET, José. Obras Completas. Tomo V. Madrid: Revista de Occidente, 1964 .

PINSART, Marie-Geneviève. Hans Jonas et la lebertè. Dimensions théologiques, ontologiques éthiques et politiques. Paris: Pour Demain, 2002.

QUILES, Ismael. Estudios sobre Ortega y Gasset Buenos Aires: Ediciones Depalma, 1991.

SGANZERLA, Anor. Natureza e responsabilidade: Hans Jonas e a biologização do ser moral. 2012. 272 f. Tese (Doutorado em Filosofia) - Universidade de São Carlos, 2012. 
WHITEHEAD, A. N. A ciência e o mundo moderno. Tradução de Hermann Herbert Watzlawick. São Paulo: Paulus, 2006.

ZIMMERMAN, M. Confronto de Heidegger com a modernidade. Tradução de João Sousa Ramos. Lisboa: Instituto Piaget, 2001.

Doutor em Filosofia (PUC-PR) Professor de Filosofia na PUC-PR

E-mail: geovainivmm@gmail.com

Doutor em Educação (UTP) Professor do IFPR/Campus Campo Largo E-mail: joelson.juik@ifpr.edu.br 